\title{
Short Course versus Standard Course of Radiotherapy in Glioblastoma Multiforme
}

\author{
May H Gaber ${ }^{1}$, Amr Y Sakr ${ }^{1 *}$, Dina H Salama², Wedad B Hashem ${ }^{1}$ and Ibrahim M EL-Zawahry² \\ ${ }^{1}$ Kasr Al-Ainy Center of Clinical Oncology and Nuclear Medicine (NEMROCK), Faculty of Medicine, Cairo University, Egypt \\ ${ }^{2}$ National Center for Radiation Research and Technology, Atomic Energy Authority, Cairo, Egypt
}

\begin{abstract}
Background: Six weeks radiotherapy plus concomitant and adjuvant temozolomide (TMZ) is the standard treatment for glioblastoma multiform (GBM). We are investigating the value of short course radiotherapy (three weeks) in comparison to the standard treatment.

Patients and Methods: Newly diagnosed patients with GBM were randomized to either short course of radiotherapy (40 Gy administered in 15 fractions over 3 weeks) plus TMZ or to standard course of radiotherapy (60 Gy administered in 30 fractions over 6 weeks) plus TMZ. Adjuvant TMZ were given to both groups. The primary end point was overall survival.

Results: 60 patients were randomized, 30 patients to short course and 30 patients to standard course. Median Overall Survival (OS) for short course was 13.7 months $(95 \% \mathrm{Cl} 10.47-16.92)$ and for standard course was 15.3 months $(95 \% \mathrm{Cl}: 8.53-22.06)$, with no statistically significant difference between the two groups (HR:1.16 (0.642.13); P-value 0.613). Median Progression free survival (PFS) for short course was 12 months (95\% Cl: 8.25 $15.74)$ and for standard course was 12.8 months (95\% Cl: $7.96-17.63)$, with no statistically significant difference between the two groups (HR:1.01 (0.57-1.78); P-value 0.969). Six months progression free survival was found $86 \%$ of patients in both groups. Assessment of response rate was done within 3 months of adjuvant TMZ. Responder patients, including complete and partial response, were seen in 7 patients $(23.3 \%)$ in short course group and 6 patients $(20 \%)$ in standard group. Regarding toxicity profile, there was no significant difference between both groups.
\end{abstract}

Conclusion: No significant difference between short course radiotherapy and standard course radiotherapy. Short course radiotherapy can be an option for the treatment of GBM.

Keywords: Glioblastoma; GBM; Hypofractionation; Brain tumors; Radiotherapy; Temozolomide

\section{Introduction}

Unfortunately, the median survival of patients with GBM, treated with surgical resection followed by six weeks radiotherapy plus concomitant and adjuvant TMZ, is around 14.6 months only [1]. Radiotherapy had an important role in treating GBM, patients with good performance status and age up to 70 years should receive standard six weeks radiation therapy, while the elderly patients (age 70 years or older) can receive short course radiation therapy [2].

Short course radiotherapy has an advantage of reduced treatment time [3]. In older patients (age 60 years or older), short course of radiation therapy is equal in median survival to standard course radiation therapy [3-5], and had a significant better survival in age older than 70 years [4]. In addition, short course radiotherapy was associated significantly with less need to increase corticosteroid dosage after finishing radiation therapy [3]. Many Phase I and phase II trials proved that the addition of TMZ to short course radiotherapy was feasible and safe [6,7]. A large phase III trial over 562 patients proved significant survival improvement for the addition of TMZ to short course radiotherapy than radiation therapy alone [8].

Short course could reduce the burden on medical resources, the patient himself and his relatives. Data on short course radiotherapy on all age groups is limited. In order to know the value of short course in all age groups, our group in Cairo University did a randomized phase II study to compare short course versus standard course in patients with GBM, not only in the elderly, but extending to include all age groups starting from patients above 18 years old. Both groups received concurrent and adjuvant TMZ.

\section{Patients and Methods}

\section{Patient criteria}

Eligible patients should fulfill all the following criteria: Pathological diagnosis of GBM, Tumor size $\leq 6 \mathrm{~cm}$, age above 18 years, ECOG performance status 0,1 and 2 with no previous radiation to brain. Exclusion criteria include patients received previous radiation to brain, Pregnant patients. All patients provided written informed consent, and the study was approved by the ethics committees of Kasr El Aini Center of Clinical Oncology and Nuclear Medicine (NEMROCK).

\section{Study design}

This prospective randomized clinical study include a total of 60 patients, recruited from Kasr El Aini Center of Clinical Oncology and Nuclear Medicine (NEMROCK) in the period from June, 2014 to

${ }^{*}$ Corresponding author: Amr Y Sakr, Kasr Al-Ainy Center of Clinical Oncology and Nuclear Medicine (NEMROCK), Faculty of Medicine, Cairo University, Egypt; E-mail: amrsakr@Kasralainy.edu.eg

Received November 12, 2018; Accepted November 23, 2018; Published November 30, 2018

Citation: Gaber MH, Sakr AY, Salama DH, Hashem WB, EL-Zawahry MI (2018) Short Course versus Standard Course of Radiotherapy in Glioblastoma Multiforme. J Nucl Med Radiat Ther 9: 388. doi: 10.4172/2155-9619.1000388

Copyright: (c) 2018 Gaber MH, et al. This is an open-access article distributed under the terms of the Creative Commons Attribution License, which permits unrestricted use, distribution, and reproduction in any medium, provided the original author and source are credited. 
February, 2016, 30 patients in each group. Patients were randomized either to short-course radiotherapy regimen (40 Gy in 15 fractions over 3 weeks) with TMZ, or to standard course radiotherapy regimen (60 Gy in 30 fractions over 6 weeks) with TMZ.

\section{Pretreatment evaluation}

All patients underwent baseline complete medical detailed history and physical examination. Laboratory studies include complete blood count, liver function test and kidney function test. Postoperative base line MRI brain evaluation with contrast, chest X-ray, abdomino-pelvic ultrasound. CT scan was done when we have a suspicious lesion in chest X-ray or abdominopelvic ultrasound.

\section{Radiation therapy}

Radiation therapy was given within 6 weeks of surgery. Patient treated with three-dimensional conformal radiotherapy, positioning with an immobilization mask system. Continuous $3 \mathrm{~mm}$ CT scans of the head was obtained with a 16-slice spiral CT scanner in supine position. The prescribed dose for the standard adjuvant RT is given as a singlephase treatment. Based on postoperative magnetic resonance imaging study, planning target volume (PTV) consisted of the enhancing tumor volume plus $2.5 \mathrm{~cm}$ margin around the tumor. Eclipse planning system version 11 was used for planning techniques. Radiation treatment was delivered with Varian unique 6 MV linear accelerator machine.

\section{Temozolomide}

TMZ was given concurrently daily during the radiation therapy at a dose of $75 \mathrm{mg}$ per square meter per day starting with the first day of radiation therapy and continue until the last day of radiation. And then as adjuvant after radiation therapy, at a dose of $200 \mathrm{mg}$ per square meter per day for five consecutive days every 28 days for 6 cycles. Adjuvant TMZ started 4 weeks after radiation therapy.

\section{Post-treatment evaluation and follow up}

Clinical evaluation was done every week during radiation and then every month during adjuvant TMZ and then every 2-3 months. Contrast-enhanced brain magnetic resonance imaging was done after radiation therapy and then every 3 months or according to the clinical condition of the patient. Second line chemotherapy was given for patients with documented disease progression and with good performance status $0-2$. Lomustin $110 \mathrm{mg} / \mathrm{m}^{2}$ orally D1 and Vincristin $1.4 \mathrm{mg} / \mathrm{m}^{2}$ (Maximum $2 \mathrm{mg}$ ) intravenous D1 and D21, cycle repeated every 6 weeks until progression or toxicity.

\section{Outcome parameters}

The primary end point of this study was overall survival. The secondary end points were progression free survival, toxicity, and response rate. Progression Free Survival (PFS) was calculated from the date of randomization till the date of documentation of disease progression, last follow up or death. Overall Survival (OS) was calculated from the date of randomization to the date of death or last follow up. Response rate was defined according to the Macdonald criteria [9]. Toxicity was defined according to Common Toxicity Criteria version 4.

\section{Statistical analysis}

All data was tabulated and statistically studied by descriptive analysis as well as survival analysis in relation to different clinicoepidemiological factors. Survival analysis was performed using Kaplan Meier method for both overall survival and progression-free survival. Univariate and multivariate analysis using COX regression module was performed to test the power of relation between the independent variables and overall survival as well as disease free survival. A probability value (P-value) less than 0.05 was considered significant. The statistical calculations were done using computer programs Microsoft Excel version 7 and SPSS (statistical package for the social science) statistical programs.

\section{Results}

Median age of all patients was 52 years (range: 18-70 years). Regarding to sex, 41 patients $(68.3 \%)$ were males and 19 patients $(31.7 \%)$ were females. The majority of our patients (38 patients; 63.3\%) had ECOG performance status 2. At the study enrollment, headache is the most common symptom seen in 41 patients $(68.3 \%)$ followed by convulsions in 25 patients (41.6\%). Parietal region was the dominant tumor site in the MRI images in 19 patients (31.7\%). Most of the patients underwent subtotal resection (26 patients; $43.3 \%$ ) and the mean diameter of postoperative tumor residual size was 3.8 $\mathrm{cm}$. Patients and tumors characteristics were generally well balanced between the two groups of patients as seen in Table 1.

Median follow up time was 26 months (range 13.5-33.7). All patients completed the specified course of radiation therapy in both groups. Total dose of concurrent temozolomide was given to all patients without need for dose modification and the median dose of TMZ was $100 \mathrm{mg}$. Four patients (6.6\%) didn't receive adjuvant TMZ as they died before start adjuvant treatment and 19 patients $(31.6 \%)$ received 2nd line chemotherapy.

\section{Response rate}

Assessment of response rate was done within 3 months of adjuvant TMZ. Responder patients (complete response + partial response) was seen in 7 patients $(23.3 \%)$ in short course and 6 patients $(20 \%)$ in standard course, while controlled patients (complete response+partial response+stable disease) were seen in 19 patients (63.3\%) in short course and 22 patients (73.3\%) in standard course.

\section{Survival analysis}

The estimated median Progression free survival (PFS) for short course is 12 months (95\%CI: 8.25-15.74) and for standard course is 12.8 months (95\%CI: 7.96-17.63), with no statistically significant difference between the two groups (HR:1.01 (0.57-1.78); P-value 0.969) as seen in Figure 1. Six months progression free survival was found in $86 \%$ of patients in both groups. The estimated median Overall Survival (OS) for short course is 13.7 months (95\%CI 10.47-16.92) and for standard course is 15.3 months (95\%CI: 8.53-22.06), also with no statistically significant difference between the two groups (HR:1.16 (0.64-2.13); P-value 0.613) as seen in Figure 2.

When evaluating the impact of different variables on OS in the two groups. In univariate analysis in the same group, we found longer overall survival with performance status (PS) 1 versus 2 in both groups as 15.3 months versus 11.4 months ( $\mathrm{p}$-value $=0.038$ ) in short course, and 20.2 months versus 11.1 months ( $p$-value=0.031) in standard course. And for patients underwent total or subtotal resection versus biopsy only as illustrated in Table 2. In multivariate analysis we found no statistically significance in correlating different variables with OS in the two groups as illustrated in Table 3 .

\section{Toxicity}

No significant difference between the treatment groups was found. However, we have non-significant more hematological toxicity in 
Page 3 of 6

\begin{tabular}{|c|c|c|c|c|c|}
\hline \multirow{2}{*}{ Characteristics } & \multicolumn{2}{|c|}{ Short course $(n=30)$} & \multicolumn{2}{|c|}{ Standard course $(n=30)$} & \multirow{2}{*}{ P-value } \\
\hline & $\mathbf{N}$ & $\%$ & $\mathbf{N}$ & $\%$ & \\
\hline Median Age by (Years) & $51 \pm 12.84$ & & $49.1 \pm 11.21$ & & 0.408 \\
\hline \multicolumn{6}{|c|}{ Age } \\
\hline$<50$ Years & 13 & -43.3 & 13 & -43.3 & \multirow{2}{*}{1} \\
\hline$\geq 50$ Years & 17 & -56.7 & 17 & -56.7 & \\
\hline \multicolumn{6}{|c|}{ Sex } \\
\hline Male & 22 & -73.3 & 19 & -63.3 & \multirow{2}{*}{0.405} \\
\hline Female & 8 & -26.7 & 11 & -36.7 & \\
\hline \multicolumn{6}{|c|}{ P.S } \\
\hline 1 & 12 & -40 & 10 & -33.3 & 0.592 \\
\hline 2 & 18 & -60 & 20 & -66.7 & \\
\hline \multicolumn{6}{|c|}{ Surgery Type } \\
\hline Biopsy & 12 & -40 & 13 & -43.3 & \multirow{3}{*}{0.428} \\
\hline Subtotal Excision & 13 & -43.3 & 13 & -43.3 & \\
\hline Total Excision & 5 & -16.7 & 4 & -15.4 & \\
\hline Pre MRI Size by $(\mathrm{cm})$ & 5.9 & \pm 1.29 & 5 & \pm 1.43 & 0.392 \\
\hline \multicolumn{6}{|c|}{ Pre MRI Size } \\
\hline$<5 \mathrm{~cm}$ & 7 & -23.3 & 12 & -40 & \multirow{2}{*}{0.165} \\
\hline$\geq 5 \mathrm{~cm}$ & 23 & -76.7 & 18 & -60 & \\
\hline \multicolumn{6}{|c|}{ Lesion Site by lobes } \\
\hline Thalamic and Pineal Body & 0 & 0 & 4 & -15.4 & \multirow{5}{*}{0.389} \\
\hline Frontal & 8 & -26.7 & 7 & -23.3 & \\
\hline Temporal & 9 & -30 & 8 & -26.7 & \\
\hline Parietal & 10 & -33.3 & 9 & -30 & \\
\hline Occipital & 3 & -10 & 3 & -10 & \\
\hline
\end{tabular}

Table 1: Patient and tumor characteristics.

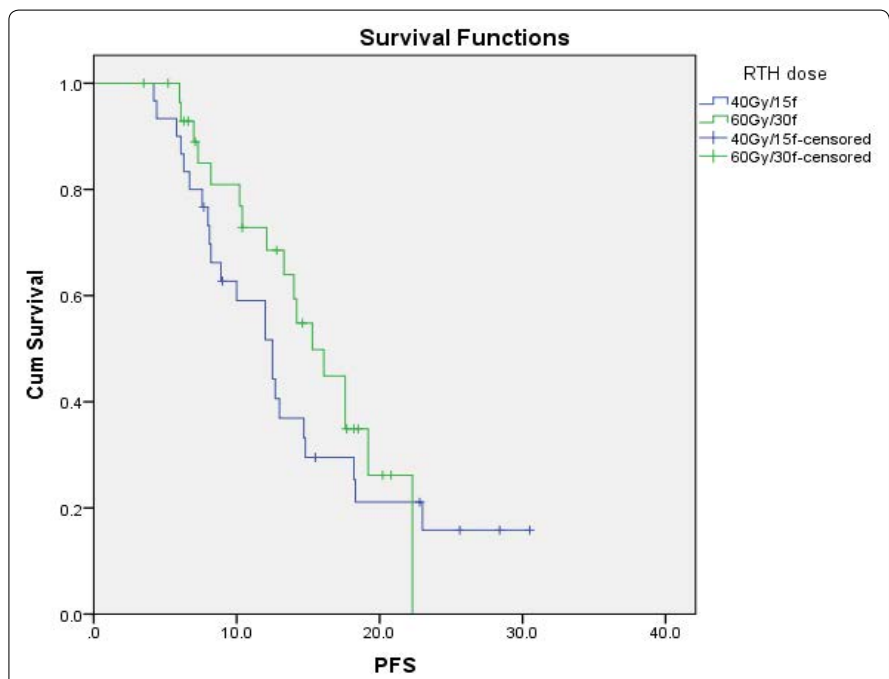

Figure 1: Progression free survival (PFS) between the 2 arms groups.

standard course. Also we found more non-significant GIT toxicity in the form of anorexia (12 patient; $40 \%$ ) and vomiting (12 patient; $40 \%$ ) in the standard course. Grade 3 fatigue is reported in one patient $(3.3 \%)$ in short course. The main adverse events of the two groups of patients are summarized in Table 4.

\section{Discussion}

The idea of hypofractionation in GBM is very attractive, as the disease is very common and has a poor prognosis with the standard treatment. However, we have only limited number of trials addressing this type of treatment in all age groups. Selected trials are illustrated in

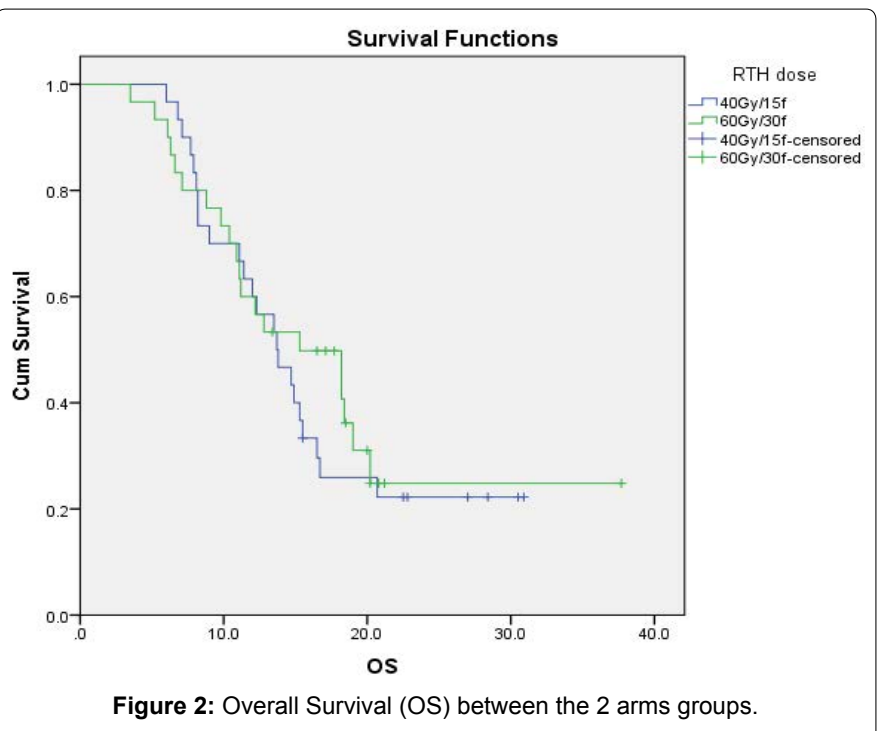

Table 5, the trials mainly started in the elderly with bad performance status. Currently hypofractionation radiation therapy became established in the elderly, especially patients above 70 years old. The concomitant use of TMZ with hypofractionation provided a significant survival advantage. From my prespective, it is very important to test the hypofractionation theory in all age groups as increasing the dose per fraction with concomitant use of TMZ can improve the outcome results and decrease the treatment cost and time.

There are different schedules of hypofractionation, ranging from 2 or 3 up till 4 weeks, with or without TMZ. In our study, we chose the schedule of 40 Gy in 15 fractions over 3 weeks, which is identical to 
Citation: Gaber MH, Sakr AY, Salama DH, Hashem WB, EL-Zawahry MI (2018) Short Course versus Standard Course of Radiotherapy in Glioblastoma Multiforme. J Nucl Med Radiat Ther 9: 388. doi: 10.4172/2155-9619.1000388

Page 4 of 6

\begin{tabular}{|c|c|c|}
\hline Variable & Short course $(n=30)$ & Standard course $(n=30)$ \\
\hline \multicolumn{3}{|c|}{ Age } \\
\hline$<50$ years & 13.7 & 18.4 \\
\hline$\geq 50$ years & 13.8 & 12.8 \\
\hline P-value & 0.413 & 0.096 \\
\hline \multicolumn{3}{|c|}{ Mass Size } \\
\hline$<5 \mathrm{~cm}$ & 15.3 & 18.2 \\
\hline$\geq 5 \mathrm{~cm}$ & 13.5 & 12.2 \\
\hline P-value & 0.549 & 0.321 \\
\hline \multicolumn{3}{|c|}{ Surgery Type } \\
\hline Biopsy & 11.1 & 8.8 \\
\hline Subtotal Excision & 16.7 & 19 \\
\hline Total Excision & 15.5 & 20 \\
\hline P-value & 0 & 0 \\
\hline \multicolumn{3}{|c|}{ Sex } \\
\hline Male & 12.3 & 12.8 \\
\hline Female & 16.5 & 18.2 \\
\hline P-value & 0.089 & 0.808 \\
\hline \multicolumn{3}{|c|}{ P.S } \\
\hline 1 & 15.3 & 20.2 \\
\hline 2 & 11.4 & 11.1 \\
\hline $\mathrm{P}$-value & 0.038 & 0.031 \\
\hline \multicolumn{3}{|c|}{ Lesion Site } \\
\hline Rt & 13.8 & 18.2 \\
\hline Lt & 13.5 & 12.2 \\
\hline Central & NA & 8.8 \\
\hline P-value & 0.604 & 0.504 \\
\hline \multicolumn{3}{|c|}{ Lesion Site by lobes } \\
\hline central & NA & 6.1 \\
\hline Frontal & 15.5 & 20.2 \\
\hline Temporal & 9 & 12.8 \\
\hline Parietal & 13.8 & 18.2 \\
\hline Occipital & 11.4 & 11.1 \\
\hline P-value & 0.183 & 0.5 \\
\hline
\end{tabular}

Table 2: Correlation with O.S in Same group in univariate analysis.

\begin{tabular}{|c|c|c|c|c|c|c|c|}
\hline Variable & $\begin{array}{l}\text { Short course } \\
(n=30)\end{array}$ & $\begin{array}{l}\text { Standard course } \\
(n=30)\end{array}$ & P-value & Std. err & HR & Lower $95 \% \mathrm{Cl}$ & Upper $95 \% \mathrm{Cl}$ \\
\hline \multicolumn{8}{|c|}{ Age } \\
\hline$<50$ years & 13.7 & 18.4 & 0.523 & 0.454 & 1.401 & 0.498 & 3.946 \\
\hline$\geq 50$ years & 13.8 & 12.8 & 0.775 & 0.384 & 1.116 & 0.526 & 2.369 \\
\hline \multicolumn{8}{|c|}{ Mass Size } \\
\hline$<5 \mathrm{~cm}$ & 15.3 & 18.2 & 0.682 & 0.559 & 1.272 & 0.403 & 4.022 \\
\hline$\geq 5 \mathrm{~cm}$ & 13.5 & 12.2 & 0.935 & 0.349 & 1.03 & 0.503 & 2.111 \\
\hline \multicolumn{8}{|c|}{ Surgery Type } \\
\hline Biopsy & 11.1 & 8.8 & 0.615 & 0.412 & 0.541 & 2.821 & 1.847 \\
\hline Subtotal Excision & 16.7 & 19 & 0.736 & 0.524 & 0.3 & 2.342 & 3.334 \\
\hline Total Excision & 15.5 & 20 & 0.259 & 1.168 & 0.378 & 36.818 & 36.818 \\
\hline $\begin{array}{l}\text { Resection (subtotal } \\
\text { and total) }\end{array}$ & 16.5 & 20.2 & 0.36 & 0.497 & 0.609 & 3.833 & \\
\hline \multicolumn{8}{|c|}{ Sex } \\
\hline Male & 12.3 & 12.8 & 0.44 & 0.371 & 1.332 & 0.644 & 2.756 \\
\hline Female & 16.5 & 18.2 & 0.541 & 0.618 & 0.685 & 0.204 & 2.301 \\
\hline \multicolumn{8}{|c|}{ P.S } \\
\hline 1 & 15.3 & 20.2 & 0.601 & 0.589 & 1.361 & 0.429 & 4.32 \\
\hline 2 & 11.4 & 11.1 & 0.746 & 0.367 & 1.126 & 0.548 & 2.313 \\
\hline \multicolumn{8}{|c|}{ Lesion Site } \\
\hline Rt & 13.8 & 18.2 & 0.213 & 0.457 & 1.766 & 0.721 & 4.324 \\
\hline
\end{tabular}




\begin{tabular}{|c|c|c|c|c|c|c|c|}
\hline Lt & 13.5 & 12.2 & 0.61 & 0.495 & 0.777 & 0.294 & 2.051 \\
\hline \multicolumn{8}{|c|}{ Lesion Site by lobes } \\
\hline $\begin{array}{l}\text { Thalamic and } \\
\text { Pineal Body }\end{array}$ & NA & 6.1 & $x$ & $x$ & $x$ & $x$ & $x$ \\
\hline Frontal & 15.5 & 20.2 & 0.87 & 0.683 & 0.894 & 0.234 & 3.41 \\
\hline Temporal & 9 & 12.8 & 0.532 & 0.579 & 1.437 & 0.462 & 4.473 \\
\hline Parietal & 13.8 & 18.2 & 0.593 & 0.588 & 1.37 & 0.432 & 4.34 \\
\hline Occipital & 11.4 & 11.1 & 0.695 & 0.926 & 1.437 & 0.234 & 8.816 \\
\hline
\end{tabular}

Table 3: Shows correlation with O.S between two arms in multivariate analysis.

\begin{tabular}{|c|c|c|c|c|c|}
\hline & \multicolumn{2}{|c|}{ Short course } & \multicolumn{2}{|c|}{ Standard course } & \multirow{2}{*}{ P-value } \\
\hline & $\mathbf{N}$ & $\%$ & $\mathbf{N}$ & $\%$ & \\
\hline \multicolumn{6}{|c|}{ Anemia } \\
\hline Grade 1 & 7 & 23.3 & 9 & 30 & \multirow[t]{2}{*}{0.824} \\
\hline Grade 2 & 1 & 3.3 & 2 & 6.7 & \\
\hline \multicolumn{6}{|c|}{ Neutropenia } \\
\hline Grade 1 & 2 & 6.7 & 2 & 6.7 & \multirow[t]{2}{*}{0.964} \\
\hline Grade 2 & 0 & 0 & 0 & 0 & \\
\hline \multicolumn{6}{|c|}{ Thrombocytopenia } \\
\hline Grade 1 & 3 & 10 & 5 & 16.7 & \multirow[t]{2}{*}{0.706} \\
\hline Grade 2 & 0 & 0 & 0 & 0 & \\
\hline \multicolumn{6}{|c|}{ Vomiting } \\
\hline Grade 1 & 11 & 36.7 & 12 & 40 & \multirow[t]{2}{*}{0.546} \\
\hline Grade 2 & 2 & 6.7 & 0 & 0 & \\
\hline \multicolumn{6}{|c|}{ Alopecia } \\
\hline Grade 1 & 21 & 70 & 19 & 63.3 & \multirow[t]{2}{*}{0.401} \\
\hline Grade 2 & 8 & 26.7 & 10 & 33.3 & \\
\hline \multicolumn{6}{|c|}{ Fatigue } \\
\hline Grade 1 & 13 & 43.3 & 16 & 53.3 & \multirow{3}{*}{0.292} \\
\hline Grade 2 & 3 & 10 & 6 & 20 & \\
\hline Grade 3 & 1 & 3.3 & 0 & 0 & \\
\hline \multicolumn{6}{|c|}{ Insomnia } \\
\hline Grade 1 & 1 & 3.3 & 3 & 10 & \multirow[t]{2}{*}{0.569} \\
\hline Grade 2 & 6 & 20 & 7 & 23.3 & \\
\hline \multicolumn{6}{|c|}{ Seizure } \\
\hline Grade 1 & 11 & 36.7 & 7 & 23.3 & \multirow[t]{2}{*}{0.368} \\
\hline Grade 2 & 2 & 6.7 & 5 & 16.7 & \\
\hline \multicolumn{6}{|c|}{ Headache } \\
\hline Grade 1 & 14 & 46.7 & 16 & 53.3 & \multirow[t]{2}{*}{0.322} \\
\hline Grade 2 & 4 & 13.4 & 7 & 23.3 & \\
\hline \multicolumn{6}{|c|}{ Anorexia } \\
\hline Grade 1 & 6 & 20 & 12 & 40 & \multirow[t]{2}{*}{0.095} \\
\hline Grade 2 & 0 & 0 & 1 & 3.3 & \\
\hline
\end{tabular}

Table 4: Incidence of adverse events post concurrent chemoradiation.

the early American short course schedule published in 2004 [3]. It was also used by Perry and his colleagues in a large multicenter trial for the elderly patients [8]. The Nordic study gives a 2 -week schedule. However, it is given without TMZ. The addition of TMZ to the short course of radiation therapy was very safe and effective. A large multicenter phase III trial has proved a significant survival improvement with the addition of TMZ [8]. In our study, the combination was very safe.

In our study, the median overall survival was not statistically different between standard and short course, which makes it consistent with the Canadian data published by Roa et al. However, it is different from the Canadian trial by Azoulay et al, which documented the inferior survival for the three weeks arm (40 Gy in 15 fractions over 3 weeks) relative to the standard course and the four- week course (60 Gy in 20 fractions over 4 weeks). We believe that the difference can be explained by the fact that it was a retrospective study, with a high percentage of patients $(81.4 \%) \geq 65$ years in the three-week group relative to only $22.4 \%$ in the standard group. In addition, only $55.8 \%$ from the threeweek group received TMZ relative to $95.2 \%$ in the standard group [10]. We found a relatively high median overall survival than documented in the Nordic, Roa, Azoulay and Perry trials. This may be due to the recruitment of a younger age group, better performance status and the use of concurrent and adjuvant TMZ. That makes it consistent with the overall survival documented in a trial done over all age groups and with the use of TMZ $[6,7,11]$.

As with previous studies over GBM, performance status and resection of the tumor were found to be the most important factors for the overall survival. Several clinical studies have indicated that O6-methylguanine-DNA methyltransferase (MGMT) promoter 


\begin{tabular}{|c|c|c|c|c|c|c|}
\hline Author & Trial Type & Age & Scheudule & $\mathbf{N}$ & os & Finding \\
\hline \multirow{2}{*}{ Roa [3] } & \multirow{2}{*}{ Phase III } & \multirow{2}{*}{$\geq 60$} & SRT $60 \mathrm{~Gy} / 30 \mathrm{fr} / 6 \mathrm{wks}$ & 47 & 5.1 & \multirow{2}{*}{ No difference in survival } \\
\hline & & & HRT $40 \mathrm{~Gy} / 15 \mathrm{fr} / 3 \mathrm{wks}$ & 48 & 5.6 & \\
\hline \multirow{3}{*}{ Malmström [4] } & \multirow{3}{*}{ Phase III } & \multirow{3}{*}{$\geq 70$} & Temozolomide & 93 & 8.3 & \multirow{3}{*}{$\begin{array}{l}\text { Poor outcome with standard } \\
\text { radiotherapy. }\end{array}$} \\
\hline & & & SRT $60 \mathrm{~Gy} / 30 \mathrm{fr} / 6 \mathrm{wks}$ & 98 & 7.5 & \\
\hline & & & HRT $34 \mathrm{~Gy} / 10 \mathrm{fr} / 2$ wks & 100 & 6 & \\
\hline Reddy [6] & Phase II & All & HRT 60 Gy/10 fr/2 wks+TMz & 24 & 16.6 & $\mathrm{HRT}+\mathrm{TMZ}$ is safe \\
\hline \multirow{2}{*}{ Jastaniyah [7] } & \multirow{2}{*}{ Phase I } & \multirow{2}{*}{ All } & HRT 54.4 Gy/20 fr/4 wks+TMZ (76\%) & \multirow{2}{*}{25} & \multirow{2}{*}{15.6} & \multirow{2}{*}{$\mathrm{HRT}+\mathrm{TMZ}$ is feasible and safe. } \\
\hline & & & HRT 60 Gy/22 fr/4.5 wks+TMZ (76\%) & & & \\
\hline \multirow{3}{*}{ Azoulay [10] } & \multirow{3}{*}{ Retrospective } & \multirow{3}{*}{ All } & SRT 60 Gy/30 fr/6 wks+TMZ & 147 & 16 & \multirow{3}{*}{$\begin{array}{l}\text { HF60 is equal to SRT, both are } \\
\text { significantly better than HF40. }\end{array}$} \\
\hline & & & HF60 $60 \mathrm{~Gy} / 20 \mathrm{fr} / 4$ wks+TMZ & 86 & 15 & \\
\hline & & & HF40 40 Gy/15 fr/3 wks+TMZ (55\%) & 43 & 8 & \\
\hline \multirow{2}{*}{ Carlson [11] } & \multirow{2}{*}{ Randomized phase II } & \multirow{2}{*}{ All } & HRT 60 Gy/10 fr/2 wks+TMz & 26 & 16.3 & \multirow{2}{*}{$\begin{array}{l}\text { No survival benefit for the addition } \\
\text { of BEV. }\end{array}$} \\
\hline & & & HRT 60 Gy/10 fr/2 wks+TMZ+BEV & 30 & 16.3 & \\
\hline \multirow{2}{*}{ Perry [8] } & \multirow{2}{*}{ Phase III } & \multirow{2}{*}{$\geq 65$} & HRT $40 \mathrm{~Gy} / 15 \mathrm{fr} / 3$ wks & 281 & 7.6 & \multirow{2}{*}{$\begin{array}{c}\text { Survival benefit for the addition of } \\
\text { TMZ }\end{array}$} \\
\hline & & & HRT 40 Gy/15 fr/3 wks+TMZ & 281 & 9.3 & \\
\hline \multirow{2}{*}{ Current Study } & \multirow{2}{*}{ Randomized phase II } & \multirow{2}{*}{ All } & SRT $60 \mathrm{~Gy} / 30 \mathrm{fr} / 6 \mathrm{wks}+\mathrm{TMz}$ & 30 & 15.3 & \multirow{2}{*}{ No significant difference } \\
\hline & & & HRT 40 Gy/15 fr/3 wks+TMz & 30 & 13.7 & \\
\hline
\end{tabular}

SRT: Standard Radiation Therapy. HRT: Hypofractionated Radiation Therapy. TMZ: Temozolomide. HF:Hypofractionated. BEV: Bevacizumab. N: Number of patients. OS: Overall Survival (in months).

Table 5: Selected trials of hypofractionation in GBM.

methylation is associated with improved overall survival $[4,8]$. However, we did not assess MGMT due to a financial issue and as all the patients were planned to receive TMZ as concomitant and adjuvant with radiation.

Regarding pseudoprogression, which has been reported in variable incidence, we believe that it may be related to the timing of the imaging post radiation as the later the imaging, the fewer the incidents of pseudoprogression. We usually do the imaging 3 months post radiation, therefore, we did not find any cases with pseudoprogression. All the cases were true progression.

Short course treatment is relatively associated with less hematological and non-hematological toxicity as a result of half-time treatment duration of TMZ (3 weeks versus 6 weeks). There were no side effects documented from increasing the dose per fraction of radiotherapy from 2 Gy up to $2.66 \mathrm{~Gy}$.

In countries with moderate to low income and a relatively low health budget, the cost of the treatment is very important, specifically when we deal with a fatal disease that has dismal prognosis like GBM. In those cases, the short course schedule is very essential as it decreases the time of radiation therapy and the dose of adjuvant TMZ by $50 \%$.

In conclusion, short course radiotherapy is comparable to the standard course in the treatment of GBM. Accordingly, three weeks radiation therapy concomitant with TMZ followed by adjuvant TMZ can be an option for the treatment of GBM, especially in countries with limited resources.

\section{References}

1. Stupp R, Mason WP, van den Bent MJ, Weller M, Fisher B, et al. (2005) Radiotherapy plus concomitant and adjuvant temozolomide for Glioblastoma. N Engl J Med 352: 987-996.
2. Cabrera AR, Kirkpatrick JP, Fiveash J, Shih HA, Koay E, et al. (2016) Radiation therapy for glioblastoma: executive summary of an American Society for radiation oncology evidence-based clinical practice guideline. Pract Radiat Oncol 6: 217-225

3. Roa W, Brasher PMA, Bauman G, Anthes M, Bruera E, et al. (2004) Abbreviated course of radiation therapy in older patients with glioblastoma multiforme: $A$ prospective randomized clinical trial. J Clin Oncol 22: 1583-1588.

4. Malmström A, Grønberg BH, Marosi C, Stupp R, Frappaz D, et al. (2012) Temozolomide versus standard 6-week radiotherapy versus hypofractionated radiotherapy in patients older than 60 years with glioblastoma: The Nordic randomised, phase 3 trial. Lancet Oncol 13: 916-926.

5. Arvold ND, Tanguturi SK, Aizer AA (2015) Hypofractionated versus standard radiation therapy with or without temozolomide for older glioblastoma patients. Int J Radiation Oncol Biol Phys 92: 384-389.

6. Reddy K, Damek D, Gaspar LE, Ney D, Waziri A, et al. (2012) Phase II tria of hypofractionated imrt with temozolomide for patients with newly diagnosed glioblastoma multiforme. Int J Radiation Oncol Biol Phys 84: 655-660.

7. Jastaniyah N, Murtha A, Pervez N, Le D, Roa W, et al. (2013) Phase I study of hypofractionated intensity modulated radiation therapy with concurrent and adjuvant temozolomide in patients with glioblastoma multiforme. Radiation Oncology 8: 38

8. Perry JR, Laperriere N, O'Callaghan CJ, Brandes AA, Menten J, et al. (2017) Short-course radiation plus temozolomide in elderly patients with glioblastoma N Engl J Med 376: 1027-1037.

9. Macdonald DR, Cascino TL, Schold SC, Cairncross JG (1990) Response criteria for phase II studies of supratentorial malignant glioma. J Clin Oncol 8 : 1277-1280.

10. Azoulay M, Santos F, Souhami L, Panet-Raymond V, Petrecca K, et al. (2015) Comparison of radiation regimens in the treatment of Glioblastoma multiforme: results from a single institution. Radiation Oncology 10: 106.

11. Carlson JA, Reddy K, Laurie LE, Gaspar LE, Ney D (2015) Hypofractionatedintensity modulated radiotherapy (hypo-IMRT) and temozolomide (TMZ) with or without bevacizumab (BEV) for newly diagnosed glioblastoma multiforme (GBM): A comparison of two prospective phase II trials. J Neuro Oncol 123 251-257. 